\title{
Variations
}

Variations

Revue internationale de théorie critique

$13 / 14 \mid 2010$

Le choix du petit

\section{Subjectivités rebelles contre identité nationale}

\section{Lucia Sagradini}

\section{(2) OpenEdition}

Journals

Édition électronique

URL : http://journals.openedition.org/variations/168

DOI : 10.4000/variations. 168

ISSN : 1968-3960

\section{Éditeur}

Les amis de Variations

\section{Édition imprimée}

Date de publication : 31 mars 2010

\section{Référence électronique}

Lucia Sagradini, «Subjectivités rebelles contre identité nationale », Variations [En ligne], 13/14 | 2010,

mis en ligne le 01 février 2012, consulté le 20 avril 2019. URL : http://journals.openedition.org/

variations/168; DOI : 10.4000/variations.168

Ce document a été généré automatiquement le 20 avril 2019.

Les ami•e•s de Variations 


\title{
Subjectivités rebelles contre identité nationale
}

\author{
Lucia Sagradini
}

\section{NOTE DE L'ÉDITEUR}

Première publication sur www.theoriecritique.com, « Le choix du petit », Printemps 2010, pp. 7-11

\section{Souvenir d'enfance}

1 Je revois encore mon grand-père, assis au fond d'un siège de taxi, me montrant du doigt les merveilles de Buenos Aires, en pleine dictature, les yeux brillants. Tout d'un coup, il me parle de la France - terre d'asile pour les étrangers- et se met à chanter La Marseillaise. Fier et heureux de nous savoir hors de danger, nous, sa famille, ses filles et ses petits-enfants, depuis que nous nous étions enfuis, et profitant de mon passage dans la capitale, envoyée par des parents soucieux que je connaisse malgré tout mon pays.

2 Alors qu'il n'a jamais quitté son pays, vivant dans une semi-clandestinité, un des rares avocats à continuer de déposer les demandes d'habeas corpus, alors que le régime autoritaire poursuivait l'oppression de tous les potentiels ennemis de l'intérieur, mon grand-père croyait dur comme fer à cet idéal de la république française, lieu d'accueil de tous les opprimés. C'est en partie cet idéal qui a fait qu'il pouvait continuer à endurer la violence de la répression, survivre à l'incarcération, aux sévices, à la vision des dépouilles pour identifier les victimes, car il savait que quelque part des idées héritées de la révolution donnaient une chance à celui qui est en danger de mort. 


\section{Destruction}

3 Les principes à l'origine de cette république française - liberté-égalité fraternité - nous ont réuni, nous les étrangers et les Français, et nous ont conduit vers ce pays, perçu alors comme une utopie. Celle d'arriver à être accueillis avec nos horribles oripeaux, portant la puanteur d'une tragédie politique ou économique avec l'illusion de trouver en France la possibilité d'un sauvetage. D'une main secourable. Une idée de secours qui en fait a permis à la démocratie de croître. Pourtant, depuis trente ans, les formes du politique signalent par leur rhétorique, leur action et leurs prises de décisions que ce principe, fondement du vivre ensemble et de la démocratie, n'a plus cours. Ses valeurs sont périmées, à la manière d'une inscription élimée sur le dos d'une vielle pièce de monnaie. Comme s'avère périmée la citoyenneté de tous ceux qui ne peuvent pas présenter leur acte de naturalisation ou celui des générations précédentes.

4 Aujourd'hui, d'une certaine manière, le fait que mon grand-père soit mort est une chance, car il ne pourrait en aucune façon se raccrocher à cet idéal pour lutter. Cet idéal n'est plus. Il n'existe plus, car depuis des années, la structure de gouvernance (gauche-droite confondues) réalise un travail de destruction des principes qui ont fondé la démocratie issue de la Révolution : liberté, égalité, fraternité. En 1793 - l'an II - la Constitution prévoyait que toute personne vivant sur le sol républicain pouvait prétendre à la citoyenneté. Ces principes qui sont le socle fécond d'une démocratie à la française sont érodés de manière parfois progressive et lente, parfois de façon rapide et brutale. Force est de remarquer que l'Etat français se déploie dans une destruction massive de tous les acquis politiques et sociaux venus de 1789 comme de l'après-guerre et de Mai 68 .

5 La question de l'asile fait aux étrangers a subi la première secousse idéologique et politique lorsque Rocard a détruit l'un des principes organisateurs de la démocratie dans laquelle nous vivions, déclamant, fier de lui, que la France ne peut pas accueillir toute la misère du monde. Ce virage qui succédait au renoncement de faire voter les étrangers aux élections alors que les gens qui avaient élu Mitterrand l'avaient appelé, cette phrase a été la mine dans laquelle tous les partis confondus sont venus puiser pour asseoir une politique de gouvernement qui a fini d'anéantir, en bientôt trente ans, la place faite à l'autre.

\section{Démocratie}

Dans le même temps, il serait candide de croire que cela atteint seulement (sic!) la place que nous donnons à l'altérité. Il y a un travail de sape majeur de ce qui a construit le vivre ensemble, au moment même où le monde est frappé par une crise économique et écologique profonde, qu'il apparaît dans les sondages que les citoyens ne sont pas inquiets concernant les étrangers mais beaucoup plus sur des questions d'emplois et de rémunération. Cependant, cette action de l'Etat comme superstructure a néanmoins entraîné un délitement des liens qui nous unissent tous dans cette histoire commune et ce vivre ensemble que nous devons réussir à créer chaque jour. Le gouvernement Sarkozy c'est la victoire de la réaction, la victoire de l'érosion du souffle et du projet démocratique qui vient de la Révolution de 89 à mai 68, la victoire de l'identité nationale sur la liberté. 
7 Alors que la droite risque de subir une défaite aux élections régionales, Emmanuel Todd, qui est très fin, peut dire dans les pages du Monde et sans hésitation, que l'intégration à la française marche très bien. Il n'en reste pas moins que ce qui se tient en dessous du débat sur l'identité nationale est la répression faite à tous ceux et celles qui sont différents, étrangers, entre autres choses. L'enjeu qui est en filigrane aujourd'hui est celui d'enregistrer que l'Etat français a depuis trente ans une dynamique qui s'organise dans une action contre la société qui, elle, l'a fondé. Et sur les principes qu'elle s'était choisie, cette société française.

\section{Multitude}

8 Alors aujourd'hui, nous sommes conduit à faire un choix : celui de défendre notre idéal démocratique contre l'Etat lui-même. Non seulement, nous devons l'affronter dans nos luttes personnelles. Ainsi, par exemple, en 2014, il y a de fortes chances que je ne sois plus française, si je ne peux apporter un papier pour renouveler mon passeport. Ainsi, il faut défendre ses droits comme intermittent du spectacle, ses conditions de travail, sa condition de nounou sans papier, à tel autre sa souffrance d'être obèse, au grand professeur sa recherche, au révolté de banlieue une reconnaissance et un droit à l'existence, à l'infirmière son mode de vie et de travail, à l'avocat son tribunal, etc. Nous avons tous nos luttes à poursuivre, car nous devons chacun défendre notre intégrité et nos vies dans leur singularité. Mais nous devons aussi nous organiser pour défendre notre idéal démocratique et dans ce dessein nous devons à tout prix réussir à croiser nos luttes. Aujourd'hui, nous devons faire multitude.

9 J'en appelle à la rencontre des êtres et des groupes. C'est la seule chance que nous puissions avoir face à une gouvernance archaïque et régressive. Ensemble, reprenons conscience de nos désirs, ce sont eux qui doivent impulser la politique et faisons multitude face à un gouvernement qui finit de détruire ce sur quoi nous avons choisi de vivre ensemble : un projet utopique d'une société où chacun trouve la reconnaissance, la justice sociale et la force démocratique. Unissons nos révoltes face à l'iniquité sociale qui nous frappe tous et chacun dans notre singularité, unissons nos forces devant un gouvernement qui fait le choix des forts contre les petits. Faisons le choix du petit. Faisons le choix de l'espace public oppositionnel.

10 Construisons les ponts entre tous, de ceux qui se sont fait palper les couilles pour savoir s'ils sont mineurs et sans papier, à ceux qui se sont fait palper les couilles pour avoir dit que la police faisait mal quelque chose, à ceux et celles qui se font humilier au quotidien dans leur vie, leur existence car ils sont simplement vulnérables pour telle ou telle raison. Le pont entre 800000 gardés à vue par an, les 30000 expulsés, les 300 déchus de leur citoyenneté en France, entre les damnés de Nanterre, les damnés de la terre et les dames qui croisent le fer. Il est temps de ressaisir la politique comme ce qui nous lie les uns aux autres, au-delà de nos différences, grâce à nos différences. Il s'agit de soumettre l'identité nationale à la corrosion du non-identique. Apprêtons-nous à lutter ensemble pour la démocratie plurielle, contre l'Etat. 


\section{AUTEUR}

\section{LUCIA SAGRADINI}

Chercheuse en sociologie, Paris. 